\title{
Antisecretory factor suppresses intestinal inflammation and hypersecretion
}

\author{
E Johansson, E Jennische, S Lange, I Lönnroth
}

\begin{abstract}
Background-Antisecretory factor (AF) is a recently identified regulatory protein which inhibits the intestinal fluid secretion induced by cholera toxin.

Aims-To test the effect of AF on: (a) inflammation and hypersecretion induced by toxin A from Clostridium difficile; and (b) morphological changes and hypersecretion induced by okadaic acid (the blue mussel toxin) in rat intestinal mucosa.

Methods-Morphological changes and fluid accumulation were observed in intestinal loops challenged with $1 \mu \mathrm{g}$ of toxin A or $3 \mu \mathrm{g}$ of okadaic acid administered before or after injection of $0.1 \mu \mathrm{g}$ of recombinant AF (rAF).

Results-The cytotoxic and inflammatory reaction caused by toxin $A$ was abolished after treatment with rAF given either intraveneously or intraluminally prior to the toxin or one hour after the toxin. The intestinal fluid response induced by toxin $A$ and okadaic acid was reduced $55-80 \%$ by rAF. However, the characteristic increase in goblet cells at the tips of villi in the okadaic acid treated mucosa was not inhibited by rAF.

Conclusion-Results suggest that AF might be involved in protection against inflammation and in counteracting dehydration caused by enterotoxins. Both effects are probably mediated via the enteric nervous system.

(Gut 1997; 41: 642-645)
\end{abstract}

Department of Medical Microbiology and Immunology,

University of

Gothenburg,

Guldhedsgatan 10, 413

46 Gothenburg,

Sweden

E Johansson

I Lönnroth

Department of Clinical

Bacteriology

S Lange

Department of

Anatomy and Cell

Biology, University of

Gothenburg

E Jennische

Correspondence to:

Dr I Lönnroth.

Accepted for publication 29 May 1997
Keywords: okadaic acid; Clostridium difficile toxin A; diarrhoea; neuropeptide; S5a; rat

Bacterial enterotoxins induce fluid secretion and inflammation in the intestine. A fatal form of intestinal toxinosis is caused by toxin A from Clostridium difficile, a bacterium which frequently colonises the gut after treatment with antibiotics. ${ }^{1}$ Toxin A causes fluid secretion, inflammation, and mucosal damage in the small intestine of hamsters, rabbits, and rats $^{23}$ and is probably the main cause of pseudomembranous colitis in man. ${ }^{1}$ After an initial attachment to oligosaccharide receptors, ${ }^{4}{ }^{5}$ the toxin seems to penetrate into the mucosal epithelium and acting as an enzyme it transfers glucose residues to the G-protein rho causing rearrangement of the cytoskeleton. ${ }^{67}$ The initial cytophatic effect of toxin A on the intestinal mucosa is followed by an inflammatory response, probably via a nerve mediated effect on intestinal mast cells and neutrophils. ${ }^{89}$
Diarrhoeal shellfish poisoning appears in man after consumption of shellfish which have been contaminated with marine phytoplankton. The causative agent, okadaic acid, is produced by the plankton and induces diarrhoea, nausea, and vomiting without any inflammatory reaction. ${ }^{10}{ }^{11}$ In the rat the toxin induces rapid fluid secretion ${ }^{12}$ and a concomitant shedding of epithelial cells in the intestinal mucosa without inflammation or any apparent disruption of the epithelial barrier. ${ }^{13}$ The cellular action of okadaic acid is to inhibit cellular phosphatases types 1 and $2 \mathrm{~A}$, an action which has been demonstrated in epithelial cells, nerve cells and neutrophils. ${ }^{14} 15$

The mucosal barrier protects against the action of bacterial toxins by means of both physiological and immunological defence mechanisms. We have previously shown that antisecretory factor (AF), a protein produced in the pituitary gland and in the intestinal mucosa, reverses intestinal hypersecretion induced by bacterial enterotoxins. Thus, a small amount of porcine $\mathrm{AF}$ was able to inhibit the action of a variety of enterotoxins in the pig ${ }^{16}$ and in the rat, ${ }^{17}{ }^{18}$ including the heat labile enterotoxins from Vibrio cholerae and Escherichia coli and toxin A. With the help of antibodies raised against $\mathrm{AF}$ purified from porcine blood we were able to clone complementary DNA (cDNA) and express the human AF in $E$ coli. ${ }^{19}$ Less than one picomole of homogeneous human recombinant AF ( $\mathrm{rAF}$ ) was shown to inhibit cholera toxin induced fluid secretion in rat intestinal loops. In the present paper we describe the action of $\mathrm{rAF}$ on fluid secretion induced by toxin $\mathrm{A}$ and okadaic acid in rat small intestine. The effect of rAF on toxin A induced cytotoxicity and inflammation in rat intestinal mucosa is also described.

\section{Methods}

RECOMBINANT ANTISECRETORY FACTOR

Human rAF was expressed in $E$ coli and purified as previously described.$^{19}$ In brief, the full length cDNA was subcloned into the glutathione S-transferase (GST) expression

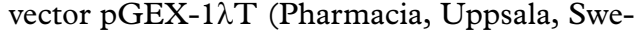
den), and the expressed fusion protein was purified on a glutathione-Sepharose column (Pharmacia) and cleaved with thrombin to elute pure rAF protein. The purity of the protein was evaluated by sodium dodecyl sulphate (SDS) polyacrylamide gel electrophoresis using Coomassie brilliant blue staining. ${ }^{19}$

ENTEROTOXINS

$C$ difficile toxin A was produced and purified as previously described ${ }^{20}$ and checked for 
homogeneity by SDS polyacrylamide gel electrophoresis. Okadaic acid was a gift from Professor Lars Edebo, Gothenburg, Sweden.

RAT INTESTINAL LOOP TEST

The study design was approved by the Ethics Committee of the University of Gothenburg. Male Sprague-Dawley rats $(300 \pm 10 \mathrm{~g})$, housed in a controlled environment, were fasted for 20 hours before experimentation but given free access to water. Intestinal secretion was investigated with the "ligated loop" method as described previously. ${ }^{21}$ Under ether anaesthesia one loop, about $10 \mathrm{~cm}$ in length, was ligated in the jejunum. The loop was challenged with $1.5 \mathrm{ml}$ of phosphate buffered saline (PBS; $0.15 \mathrm{M} \mathrm{NaCl}, 0.05 \mathrm{M}$ sodium phosphate, $\mathrm{pH}$ 7.5 ) in the control group, and in the test groups with $3 \mu \mathrm{g}$ of okadaic acid or $0.5 \mu \mathrm{g}$ of $C$ difficile toxin $\mathrm{A}$, dissolved in the same volume of PBS. Two millilitres of $0.1 \mu \mathrm{g} \mathrm{rAF}$ (experimental groups) or PBS (controls) were administrated intravenously via the dorsal vein of the penis. The animals were then allowed to wake up. The duration of challenge was five hours for toxin A and 90 minutes for okadaic acid, intervals based on findings in earlier kinetic studies of fluid accumulation induced by the respective toxins. At the end of the observation period, the rats were sacrificed by cervical spine dislocation, the abdomen was opened and the loops dissected out. The net fluid secretion $(\mathrm{mg} / \mathrm{cm})$ was estimated by subtracting the weight of a control loop from that of the experimental loop. Specimens for histological examination (see later) were taken from each loop.

ANIMAL GROUPS

Six groups of rats (I-VI) were studied, each group containing at least five animals. Rats serving as controls were subjected to $1.5 \mathrm{ml}$ of intraluminal PBS challenge in combination with intravenous $(n=6)$ or intraluminal $(n=5)$ PBS injection. Groups I and V received $2 \mathrm{ml}$ PBS by intravenous injection some 10-20 seconds before toxin challenge into the loop, while groups II and VI were injected with rAF in the same volume and by the same route. Group III was injected with rAF 60 minutes after challenge with toxin $\mathrm{A}$, while group IV was injected with rAF intraluminally just before challenge with toxin A.

HISTOLOGICAL EXAMINATION

A histological investigation of the gut wall was undertaken in all experimental groups (groups I-VI and controls without toxin). Without cut-

TABLE 1 Inhibition of toxin induced intestinal fluid secretion by recombinant antisecretory factor $(A F)$. Challenge in ligated small intestinal loops with either $1 \mu \mathrm{g} C$ difficile toxin $A$ or $3.0 \mu \mathrm{g}$ okadaic acid. AF (0.1 $\mu \mathrm{g})$, or buffer control (PBS), was injected intravenously (iv) or intraluminally (il) simultaneously or one hour after the toxin challenge

\begin{tabular}{lllll}
\hline Group & Number & Toxin challenge & AF/PBS treatment & $\begin{array}{l}\text { Fluid response } \\
(\mathrm{mg} / \mathrm{cm})\end{array}$ \\
\hline I & 7 & Toxin A & PBS (iv 0') & $484(12)$ \\
II & 5 & Toxin A & AF (iv 0') & $203(6)^{\star}$ \\
III & 6 & Toxin A & AF (iv 60') & $156(15)^{\star}$ \\
IV & 10 & Toxin A & AF (il 0') & $210(41)^{\star}$ \\
V & 5 & Okadaic acid & PBS (iv 0') & $338(5)$ \\
VI & 5 & Okadaic acid & AF (iv 0') & $151(3)^{\star}$ \\
\hline
\end{tabular}

*Significantly different from controls, $\mathrm{p}<0.05$. ting the ligated loop longitudinally, $0.5-1.0 \mathrm{~cm}$ long sections were prepared from each of the intestinal specimens. The specimens were fixed by immersion for 24 hours in $4 \%$ paraformaldehyde diluted in PBS, after which they were immersed in $7.5 \%$ sucrose solution. After at least 24 hours' incubation in the sucrose solution, the specimens were frozen on dry ice, and $5 \mu \mathrm{m}$ thick cryostat sections were prepared; at least 5-10 sections were taken from each of two different parts of the specimen-that is, a minimum of 10 and a maximum of 20 sections from each specimen. The sections were then stained with periodic acid Schiff reagents (PAS) according to routine histological procedures. Finally, the sections were rinsed in water and mounted in glycerol-gelatine.

STATISTICAL ANALYSES

Student's $t$ test for non-paired data was used for statistical analysis of the data.

\section{Results}

QUANTITATIVE ASSESSMENT OF SECRETION IN LIGATED JEJUNAL LOOPS

Five hours after challenge with $C$ difficile toxin $\mathrm{A}$ in a ligated loop, there was pronounced fluid accumulation in the loop in the absence of rAF (controls), whereas in the presence of rAF (test animals) this response was significantly reduced (table 1). Intravenous and intraluminal administration of $\mathrm{rAF}$ yielded a similar inhibition of response to toxin A (about $60 \%$ inhibition); administration of $\mathrm{rAF}$ just before or one hour after toxin challenge resulted in the same magnitude of inhibition (60-70\%). The fluid response to okadaic acid challenge was rapid and transient, the most pronounced secretion already being observed after 90 minutes. As shown in table 1 , this fluid response was also inhibited significantly by $\mathrm{rAF}(55 \%)$.

\section{MORPHOLOGY OF THE LIGATED LOOP}

The ligated loops in all experimental groups (table 1) were subjected to morphological investigation after the challenge period. Control loops were obtained from rats treated systemically and intraluminally with PBS. Figure $1 \mathrm{~A}$ shows the distinct and unchanged morphology in the controls. Severely damaged intestinal morphology is seen in fig $1 \mathrm{~B}$, showing results obtained five hours after challenge with $C$ difficile toxin A: $50-70 \%$ of the apical portion of the villi is completely destroyed, and the intestinal lumen is full of cellular debris. The architecture of the basal part of the villi is more intact, and the crypt cells along with the muscularis mucosae can be discerned. Injection of rAF intraveneously (group II) preserved the gut wall from the severe destruction by toxin A (fig 1C); the morphology of the gut wall was similar to that of the control. However, compared with the control, there was slightly more shedding of epithelial and goblet cells and some minor apical damage at the tips of the villi (not seen in fig 1C). The morphology of the mucosa in groups II, III, and IV was similar (groups III and IV not shown). The cytotoxic and inflammatory reaction caused by toxin A was thus on the whole abolished after treatment with $\mathrm{rAF}$ 


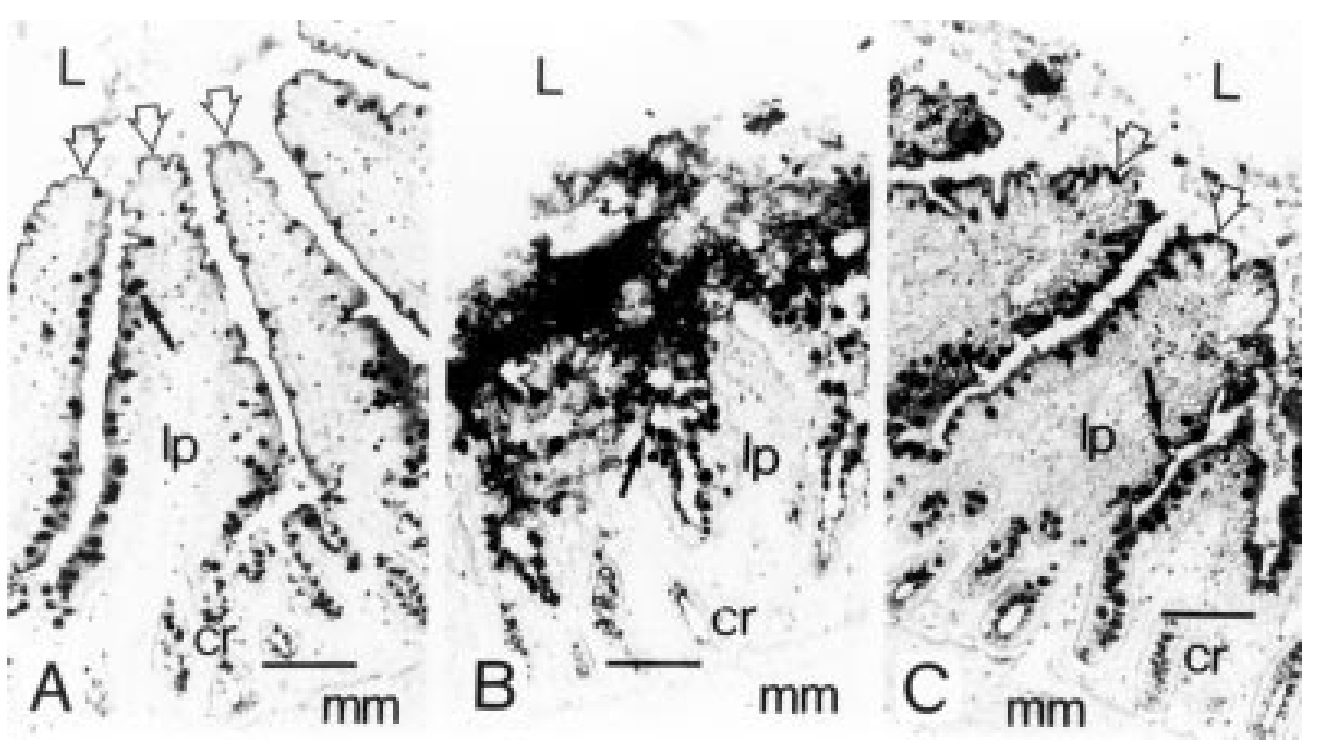

Figure 1: (A) Control morphology in ligated jejunal loop challenged with PBS. The apical parts of the villi (open arrows) are distinctly lineated against the intestinal lumen $(L)$. The lamina propria $(l p)$ is intact, as are the crypt cells $(c r)$ and muscularis mucosae (mm). The black arrow points to the black stained goblet cell. (B) Morphology in the ligated loop five hours after challenge with $C$ difficile toxin $A$. The upper half of the villi is totally disintegrated, and the intestinal morphology in this part of the villi cannot be reconstructed. The intestinal lumen is full of cell debris. The basal part of the villi shows a more intact morphology, along with the crypt cells and muscularis mucosae. (C) The intact and preserved morphology in the ligated loop despite five hours of challenge with $C$ difficile toxin $A$. Systemic injection of recombinant antisecretory factor inhibited substantially the cytotoxic action of toxin $A$. The upper half of the villi is morphologically intact; however, in the intestinal lumen some shed goblet and epithelial cells can be seen. The morphology further down the basal part of the villi and in the crypts and muscularis mucosae is identical to that of the control. Bars are $100 \mu \mathrm{m}$.

given either intravenously or intraluminally prior to or one hour after toxin challenge. Okadaic toxin does not cause inflammation in rat intestine but induces a characteristic redistribution of epithelial and goblet cells. ${ }^{13}$ These changes were not prevented by treatment with $\mathrm{rAF}$, the morphology being similar in groups $\mathrm{V}$ and VI (not shown).

\section{Discussion}

We have previously reported the inhibitory effect of rAF on cholera toxin induced intestinal fluid secretion. The results of the present study suggest that AF from human pituitary gland also inhibits intestinal fluid secretion induced by toxin A or okadaic acid in the rat. These three toxins differ from each other in their biochemical mechanism of action. Toxin A binds to receptors resembling the glycolipid B5 or $\mathrm{X} 2^{5}$ whereas cholera toxin binds to receptors resembling GM1 ganglioside. ${ }^{22}$ Their intracellular target structures and mechanisms of action also differ, toxin $\mathrm{A}$ and cholera toxin being invasive enzymes transfering glucose residues to rho and rac proteins ${ }^{7}$ and $\mathrm{ADP}$ ribosyl groups to adenylate cyclase, ${ }^{23}$ respectively; okadaic acid is a specific inhibitor of the serine/threonine specific protein phosphatases 1 and $2 \mathrm{~A} .{ }^{14}$ It should be emphasised that, despite our detailed knowledge of the biochemical action of the three toxins, it is still unclear how these activities result in fluid secretion and diarrhoea.

Treatment with rAF counteracted the cytotoxic and inflammatory activity of toxin A, further emphasising the close relation between these morphological effects and the induced hypersecretion. ${ }^{38}$ The abolition of the inflammatory reaction and the reduction in hypersecretion suggest that $\mathrm{rAF}$ or a peptide derivative of AF might be used as a drug against intestinal inflammation and hypersecretion. rAF did not inhibit the morphological effects induced by okadaic acid, whereas it inhibited the hypersecretion induced by the toxin. The toxin induced increase in goblet cells at the tips of the villi $^{13}$ thus seems to occur independently of the induced hypersecretion.

The in vitro effects of AF on nerve cells suggest that it modulates postsynaptic signals. ${ }^{24} 25$ Most of the in vivo effects exerted by AF might be explained by actions on nerve reflexes, since both intestinal fluid secretion and inflammation seem to be regulated by the enteric nerve system. Thus cholera toxin induced fluid secretion is inhibited by neuropeptides such as neuropeptide Y, somatostatin, and neurotropic drugs such as neuroleptic agents, tranquillisers, and anaesthetics. ${ }^{26-29}$ Neuronal involvment in the intestinal effects of toxin A was recently suggested by Castagliuolo et al. ${ }^{8}$ Neurotropic drugs such as lignocaine and capsaicin have been shown to reverse toxin A mediated secretion and inflammation. Whereas cholera toxin induced hypersecretion seems to be transmitted by 5 -hydroxytryptamine, ${ }^{26}$ toxin $\mathrm{A}$ induced secretion is probably mediated by substance $P$ and nitric oxide synthase. ${ }^{89}$ Thus, the afferent sensory signals triggered by cholera toxin and toxin A are probably different. AF should therefore act on the efferent neuromotor neurones which innervate the epithelium and probably control fluid transport across the mucosa. ${ }^{29}$ Okadaic acid has been studied less than the other toxins. The symptoms it causes during shellfish poisoning in humansdiarrhoea, nausea, vomiting, and abdominal pain ${ }^{11}$ - suggest a neurogenic component. Moreover, the toxin has been shown to inhibit 
the regeneration of axons in the frog sciatic sensory nerve. ${ }^{30}$

The cellular receptor for $\mathrm{AF}$ and the possible intracellular signal transduction triggered by this receptor-agonist interaction is unknown. However, AF like sequences seem to contain binding sites for polyubiquitin ${ }^{31}$ which has been shown to cause lethal diarrhoea in calves when transfected into the intestinal mucosa by means of a virus vector. ${ }^{32}$ Ubiquitin and its polymer are heat shock proteins known to be induced during various neurological ${ }^{33}$ and inflammatory bowel ${ }^{34}$ diseases. The expression of these proteins in the enteric nerve cells might lead to the release of substance $\mathrm{P}$ or 5-hydroxytryptamine involved in enterotoxic diarrhoea. The counteraction of intestinal hypersecretion and inflammation by $\mathrm{AF}$ might thus result from its interaction with polyubiquitin in enteric nerve cells.

1 Bartlett JG. Clostridium difficile: history of its role as an enteric pathogen and the current state of knowledge about the organism. Clin Infect Dis 1994; 18 (suppl 4): S265-72.

2 Lyerly DM, Saum KE, MacDonald DK, Wilkins TD. Effects of Clostridium difficile toxins given intragastrically to animals. Infect Immun 1985; 47: 349-52.

3 Torres J, Jennische E, Lange S, Lönnroth I. Enterotoxins from Clostridium difficile; diarrhoeogenic potency and morphological effects in the rat intestine. Gut 1990; 31: 781-5.

4 Krivan HC, Clark GF, Smith DF, Wilkins TD. Cell surface binding site for Clostridium difficile enterotoxin: evidence for a glycoconjugate containing the sequence Gala1for a glycoconjugate containing the sequence

5 Teneberg S, Lönnroth I, Torres JF, Galili U, ÖlvegårdTeneberg S, Lönnroth I, Torres JF, Galili U, Olvegård-
Halvarsson M, Angström J, Karlsson KA. Molecular mimHalvarsson M, Angström J, Karlsson KA. Molecular mimicry in the recognition of glycosphingolipids by $\mathrm{Gal}$ alpha 3 Gal beta 4GlcNAc beta-binding Clostridium difficile toxin A, human natural anti $\alpha$-galactosyl IgG and the mono-
clonal antibody Gal-13: characterization of a bindingactive human glycosphingolipid non-identical with the animal receptor. Glycobiology 1996; 6: 599-609.

6 Just I, Wilm M, Selzer J, Rex G, Von Eichel-Streiber C, Mann M, Aktories K. The enterotoxin from C. difficile (ToxA) monoglycosylates the Rho proteins. $f$ Biol Chen 1995; 270: 13932-6.

7 Von Eichel-Streiber C, Boquet P, Sauerborn M, Thelestam $M$. Large clostridial cytotoxins - a family of glycosyltransferases modifying small GTP-binding proteins. Trends Microbiol 1996; 4: 375-82.

8 Castagliuolo I, LaMont JT, Letourneau R, Kelly CP, O'Keane JC, Jaffer A, et al. Neuronal involvment in the intestinal effects of Clostridium difficile toxin A and Vibrio intestinal effects of Clostridium difficile toxin A and Vibrio 107: $657-65$.

9 Qui B, Pothoulakis C, Castagliuolo I, Nikulasson Z, LaMont JT. Nitric oxide inhibits rat intestinal secretion by Clostridium difficile toxin A but not Vibrio cholerae enterotoxin. Gastroenterology 1996; 111: 409-18.

10 Yasumoto T, Oshima Y, Yamagushi M. Occurence of a new type of shellfish poisoning in the Tohoku district. Bull $7 p n$ Soc Sci Fish 1978; 44: 1249-55.

11 Yasumoto T, Murata M, Oshima Y, Matsumoto GK, Clardy J. Diarrhetic shellfish toxins. Tetrahedron 1985; 41 1019-25.

12 Edebo L, Lange S, Li XP, Allenmark S. Toxic mussels and okadaic acid induce rapid hypersecretion in the rat small intestine. APMIS 1988; 96: 1029-5.
13 Lange S, Andersson GL, Jennische E, Lönnroth I, Li XP, Edebo L. Okadaic acid produces drastic histopathologic changes of the rat intestinal mucosa and with concomitant hypersecretion. In: Graneli E, Sundström B, Edler L, Anderson DM, eds. Toxic marine phytoplankton. New York: Elsevier Science, 1990: 356-61

14 Cohen P, Holmes CF, Tsukitani Y. Okadaic acid: a new probe for the study of cellular regulation. Trends Biochem Sci 1990; 15: 98-102.

15 Chiou JY, Westhead EW. Okadaic acid, a protein phosphatase inhibitor, inhibits nerve growth factor-directed neurite outgrowth in PC12 cells. 7 Neurochem 1992; 59: 1963-6.

16 Lange S, Lönnroth I, Skadhauge E. Effects of the antisecretory factor in pigs. Pflugers Arch 1987; 409: 328-32.

17 Lönnroth I, Lange S, Skadhauge E. The antisecretory factors: inducible proteins which modulate secretion in the small intestine. Comp Biochem Physiol 1988; 90: 611-7.

18 Torres J, Jennische E, Lange S, Lönnroth I. Clostridium difficile toxin $\mathrm{A}$ induces a specific antisecretory factor which protects against mucosal damage. Gut 1991; 32: 791-5.

19 Johansson E, Lönnroth I, Lange S, Jonson I, Jennische E, Lönnroth C. Molecular cloning and expression of a pituitary gland protein modulating intestinal fluid secretion. F Biol Chem 1995; 270: 20615-20.

20 Torres JF, Lönnroth I. Comparison of methods for the production and purification of toxin A from Clostridium difficile. FEMS Microbiol Lett 1988; 52: 41-6.

21 Lange $S$. A rat model for an in vivo assay of enterotoxic diarrhoea. FEMS Microbiol Lett 1982; 15: 239-42.

22 Holmgren J, Lönnroth I, Månsson JE, Svennerholm L. Interaction of cholera toxin and membrane GM1 ganglioside of small intestine. Proc Natl Acad Sci USA 1975; 72: $2520-4$

23 Gill DM. Involvment of nicotinamide adenine dinucleotide in the action of cholera toxin in vitro. Proc Natl Acad Sci USA 1975; 72: 2064-8.

24 Lange S, Lönnroth I, Palm A, Hyden H. The effect of antisecretory factor on the permeability of nerve cell membrane to chloride ion. Pflugers Arch 1987; 410: 648-51.

25 Rappalino MV, Cupello A, Lange S, Lönnroth I, Hyden H. Further studies on the effect of ASF factor on $\mathrm{Cl}$ - permeability across the Deiters neurone plasma membrane. Int $\mathcal{f}$ Neurosci 1989; 46: 93-5.

26 Lundgren O, Svanvik J, Jivegård L. Enteric nervous system. I. Physiology and pathophysiology of the intestinal tract. Dig Dis Sci 1989; 34: 264-83.

27 Yoshioka M, Asaka H, Hamada Y, Miura Y, Kobayashi K, Morishita $\mathrm{T}$, et al. Inhibitory effect of somatostatin on cholera toxin-induced diarrhea and glycoenzyme secretion in rat intestine. Digestion 1987; 36: 141-7.

28 Lönnroth I, Jennische E. Reversal of enterotoxic diarrhoea by anaesthetic and membrane-stabilizing agents. Acta Pharmacol Toxicol 1982; 51: 330-5.

29 Hansen MB, Skadhauge E. New aspects of the pathophysiology and treatment of secretory diarrhoea. Physiol Rev 1995; 44: 61-78.

30 Svensson B, Ekström PA, Edström A. Okadaic acid and cultured frog sciatic nerves: potent inhibition of axonal regeneration in spite of unaffected Schwann cell proliferation and ganglion protein synthesis. F Neurochem 1995; 64: 1000-7.

31 Van Nocker S, Deveraux Q, Rechsteiner M, Viersta RD. Arabidopsis MBP1 gene encodes a conserved ubiquitin recognition component of the $26 \mathrm{~S}$ proteasome. Proc Natl Acad Sci USA 1996; 93: 856-60.

32 Trautz N, Meyers G, Thiel HJ. Processing of poly-ubiquitin in the polyprotein of an RNA virus. Virology 1993; 197: $74-85$.

33 Lowe J, Mayer RJ. Ubiquitin, cell stress and diseases of the nervous system. Neuropathol Appl Neurobiol 1990; 16: 28191.

34 Reumaux D, Meziere C, Colobel JF, Duthilleul P, Mueller S. Distinct production of autoantibodies to nuclear components in ulcerative colitis and in Crohn's disease. Clin Immunol Immunopathol 1995; 77: 349-57. 